Obesity/insulin resistance rather than liver fat increases coagulation factor activities and expression in humans

\title{
Lallukka, Susanna
}

2017-02

Lallukka, S, Luukkonen, P K, Zhou , Y, Isokuortti , E, Leivonen , M , Juuti , A , Hakkarainen, A , Orho-Melander , M , Lundbom , N , Olkkonen, V M , Lassila , R \& Yki-Järvinen, H 2017 , ' Obesity/insulin resistance rather than liver fat increases coagulation factor activities and expression in humans ' , Thrombosis and Haemostasis , vol. 117 , no. 2 , pp. 286-294 . https://doi.org/10.1160/TH16-09-0716

http://hdl.handle.net/10138/311599

https://doi.org/10.1160/TH16-09-0716

acceptedVersion

Downloaded from Helda, University of Helsinki institutional repository.

This is an electronic reprint of the original article.

This reprint may differ from the original in pagination and typographic detail.

Please cite the original version. 
Obesity/insulin resistance rather than liver fat increases coagulation factor activities and expression in humans

Susanna Lallukka ${ }^{1,2}$, Panu K. Luukkonen ${ }^{1,2}$, You Zhou², Elina M. Petäjä ${ }^{1,2}$, Marja Leivonen $^{3}$, Anne Juuti ${ }^{3}$, Antti Hakkarainen ${ }^{4}$, Marju Orho-Melander ${ }^{5}$, Nina Lundbom ${ }^{4}$, Vesa M. Olkkonen ${ }^{2}$, Riitta Lassila ${ }^{6}$, and Hannele Yki-Järvinen ${ }^{1,2}$

1 Department of Medicine, University of Helsinki, and Helsinki University Hospital, Helsinki, Finland

2 Minerva Foundation Institute for Medical Research, Helsinki, Finland

3 Department of Surgery, University of Helsinki, and Helsinki University Hospital, Helsinki, Finland

4 Helsinki Medical Imaging Center, University of Helsinki, and Helsinki University Hospital, Helsinki, Finland

5 Department of Clinical Sciences, Diabetes and Endocrinology, University Hospital Malmö, Lund University, Malmö, Sweden

6 Coagulation Disorders Unit, Department of Hematology, and HUSLAB Laboratory Services, University of Helsinki, and Helsinki University Hospital, Helsinki, Finland

\section{Address for correspondence:}

Susanna Lallukka, M.D.; Minerva Institute for Medical Research, Biomedicum Helsinki 2U, Room DP02b, Tukholmankatu 8, 00290 HELSINKI, Finland; phone: +358 2941 25708, fax: +358-9-471 71896, e-mail: susanna.lallukkabruck@gmail.com 
Running title: Insulin resistance and coagulation factor activities

Key words: adipose tissue, inflammation, fibrinogen, insulin, non-alcoholic fatty liver disease

Word count: Abstract 239

Number of figures and tables: 3 figures and 2 tables; 5 Supplementary tables

Source of funding: This study was supported by University of Helsinki, the Doctoral Programme in Clinical Research and personal grants (S. Lallukka) from Diabetes Research Foundation, Biomedicum Helsinki Foundation and Orion Research Foundation, research grants $(\mathrm{H}$. Yki-Järvinen) from the Academy of Finland, EU/EFPIA Innovative Medicines Initiative Joint Undertaking (EMIF grant no. 115372), EU H2020 EPoS 634413, the Sigrid Juselius Foundation, the EVO grant from the Finnish government, and additionally supported by the Swedish Research Council, the Swedish Heart and Lung foundation, and the NovoNordisk Foundation (M. Orho-Melander). 


\section{Abstract}

Increased liver fat may be caused by insulin resistance and adipose tissue inflammation or by the common I148M variant in PNPLA3 at rs738409, which lacks both of these features. We hypothesized that obesity/insulin resistance rather than liver fat increases circulating coagulation factor activities. We measured plasma prothrombin time (PT, Owren method), activated partial thromboplastin time (APTT), activities of several coagulation factors, VWF:RCo and fibrinogen, and D-dimer concentration in 92 subjects divided into groups based on insulin sensitivity [insulin-resistant ('IR') vs. insulin-sensitive ('IS')] and PNPLA3 genotype (PNPLA3 ${ }^{148 M M} /{ }^{1 M l}$ vs. PNPLA3 $\left.{ }^{148 \| I}\right)$. Liver fat content $\left({ }^{1} \mathrm{H}-\mathrm{MRS}\right)$ was similarly increased in 'IR' $(13 \pm 1 \%)$ and PNPLA3 ${ }^{148 \mathrm{MM} / \mathrm{MI}}(12 \pm 2 \%)$ as compared to 'IS' $(6 \pm 1 \%, p<0.05)$ and PNPLA3 ${ }^{148 I I}(8 \pm 1 \%, p<0.05)$, respectively. FVIII, FIX, FXIII, fibrinogen and VWF:RCo activities were increased, and PT and APTT shortened in 'IR' vs. 'IS', in contrast to these factors being similar between PNPLA3 ${ }^{148 M M} / \mathrm{MI}$ and PNPLA3 ${ }^{148 \| l}$ groups. In subjects undergoing a liver biopsy and entirely lacking the I148M variant, insulin-resistant subjects had higher hepatic expression of $F 8, F 9$ and FGG than equally obese insulin-sensitive subjects. Expression of pro-inflammatory genes in adipose tissue correlated positively with PT (\% of normal), circulating FVIII, FIX, FXI, VWR:RCo and fibrinogen, and expression of anti-inflammatory genes negatively with PT (\%), FIX and fibrinogen. We conclude that obesity/insulin resistance rather than an increase in liver fat is associated with a procoagulant plasma profile. This reflects adipose tissue inflammation and increased hepatic production of coagulation factors and their susceptibility for activation. 


\section{Abbreviations}

36B4

ALT

APTT

AST

BMI

CD68

CVD

HDL

${ }^{1} \mathrm{H}-\mathrm{MRS}$

HOMA-IR

IR

IS

LDL

MCP-1

NAFLD

PNPLA3

PT

SDHA

TNF- $\alpha$

Twist1

VWF

VWF:RCo acidic ribosomal phosphoprotein 36B4

alanine aminotransferase

activated partial thromboplastin time

aspartate aminotransferase

body mass index

cluster of differentiation 68

cardiovascular disease

high-density lipoprotein

proton magnetic resonance spectroscopy

homeostatic model assessment of insulin resistance

insulin-resistant

insulin-sensitive

low-density lipoprotein

monocyte chemoattractant protein 1

non-alcoholic fatty liver disease

patatin-like phospholipase domain-containing 3

prothrombin time

succinate dehydrogenase complex, subunit $A$

tumor necrosis factor alpha

Twist-related protein 1

von Willebrand factor

von Willebrand factor ristocetin cofactor activity 


\section{Introduction}

Recent studies have shown that non-alcoholic fatty liver disease (NAFLD) is heterogeneous [1]. Insulin resistance, obesity and systemic low-grade inflammation characterise 'Metabolic NAFLD' and predispose to type 2 diabetes, venous thrombosis and cardiovascular disease (CVD) $[2,3]$. A common gene variant with a worldwide prevalence of $30-50 \%$ in the patatin-like phospholipase domain-containing 3 gene (PNPLA3) (rs738409; C>G/I148M) increases the risk of NAFLD, independently of obesity [4]. It increases liver fat in both humans and animal models but does not alter insulin sensitivity [4-6]. Thus, carriers of the I148M gene variant are neither more obese nor do they have changes in glucose or insulin concentrations or inflammation in adipose tissue $[7,8]$. The latter seems critical for the development of insulin resistance in the liver [9-11]. NAFLD caused by the I148M variant does not associate with an increased risk of diabetes or CVD [2].

Hepatocytes or sinusoidal endothelial cells in the liver are major sites of production of coagulation factors [12,13]. In NAFLD, activities of coagulation factors such as FVII [14], FVIII [15], FIX [15], FXI [15], FXII [15], von Willebrand factor (VWF) [15,16] and fibrinogen $[15,16]$ are all increased. These changes augment the risk of venous thrombosis and of atherothrombotic vascular disease $[17,18]$. It is, however, unknown whether the increase in coagulation factors in NAFLD is due to obesity/insulin resistance and associates with adipose tissue inflammation or due to increased liver fat content per se. NAFLD caused by the PNPLA3 I148M variant thus provides a model in which steatosis can be dissociated from obesity/insulin resistance. Coagulation factor activities have not been studied in different types of NAFLD. 
The mechanisms underlying increased activities of coagulation factors in NAFLD are unclear. Expression of coagulation factors in the human liver has not been compared between insulin resistant and sensitive subjects. Adipose tissue in insulin-resistant subjects over-expresses pro-inflammatory cytokines and chemokines, but shows decreased expression of anti-inflammatory adipokines [9,19-21]. These changes impair insulin action, such as regulation of platelet-collagen interaction [22], and stimulate synthesis of hepatic acute phase reactants and coagulation factors, such as fibrinogen, FVIII, and FXIII [23-25].

In the present study, we hypothesized that i) coagulation factor activities are higher in subjects with increased liver fat content associated with obesity/insulin resistance than in subjects with increased liver fat content due to PNPLA3 I148M variant, ii) coagulation factor production as judged from hepatic expression is upregulated in insulin-resistant subjects with excessive liver fat, and iii) adipose tissue inflammation correlates with circulating coagulation factor activities. To this end, we studied, in representative groups of subjects, circulating coagulation factor activities, their expression in liver biopsies and expression of pro- and anti-inflammatory cytokines/chemokines in biopsies of adipose tissue. 


\section{Methods}

Subjects and study designs

Circulating coagulation factor activities. To examine the impact of the PNPLA3 I148M variant on plasma coagulation factors, we recruited 92 subjects based on the following inclusion criteria: i) age 18 to 75 years; ii) no known acute or chronic disease except for obesity, hypertension, or NAFLD based on medical history, physical examination and standard laboratory tests (complete blood count, serum creatinine, thyroid-stimulating hormone, sodium and potassium concentrations) and ECG; iii) alcohol consumption less than $20 \mathrm{~g}$ per day in women and less than $30 \mathrm{~g}$ per day for men. None of the study subjects had type 2 diabetes. The subjects were divided based on their PNPLA3 genotype at rs738409 into those with (PNPLA3 ${ }^{148 \mathrm{MM} / \mathrm{MI})}$ and without (PNPLA3 ${ }^{148 \mid l}$ ) the I148M variant. The subjects were also divided based on median homeostatic model assessment of insulin resistance (HOMA-IR) into insulin-resistant 'IR' and insulin-sensitive 'IS' groups. Clinical characteristics of these groups are shown in Table 1.

Since both obesity/insulin resistance and the PNPLA3 I148M variant are common, we also analyzed coagulation factors in a 2 by 2 fashion in four subgroups of subjects who had both risk factors, i.e. both insulin resistance and the I148M variant ('double trouble'

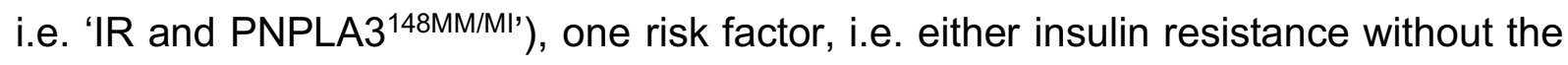
gene variant ('single trouble IR' i.e. 'IR and PNPLA3 ${ }^{148 \mid l ')}$ or carried the PNPLA3 I148M

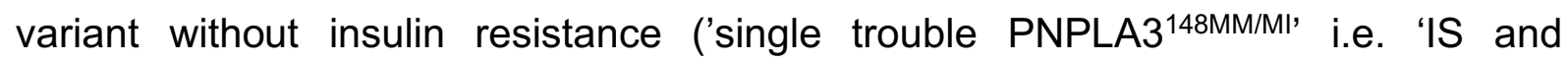

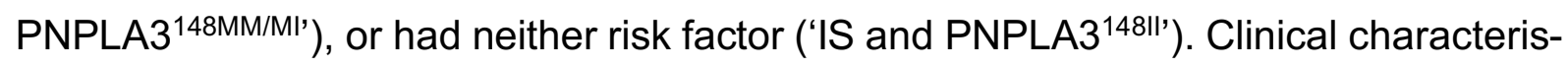
tics are shown in Supplementary Table 1.

Gene expression of coagulation factors in the human liver. We determined whether changes in circulating coagulation factors in insulin-resistant subjects with increased 
liver fat content but lacking PNPLA3 I148M gene variant were due to changes in their hepatic expression. For that purpose, we recruited consecutive subjects undergoing bariatric surgery, in whom a liver biopsy was clinically indicated. Inclusion criteria were: i) age 18 to 65 years; ii) no known acute or chronic disease, except for obesity, hypertension, NAFLD or type 2 diabetes based on medical history, physical examination, standard laboratory tests (complete blood count, serum creatinine, thyroid-stimulating hormone, sodium and potassium concentrations) and ECG; iii) daily alcohol consumption less than $20 \mathrm{~g}$ in women and less than $30 \mathrm{~g}$ for men; (iv) no history of use of toxins or drugs influencing liver steatosis; and (v) no use of any anticoagulant drugs.

The subjects were invited to a separate clinical visit one week prior to surgery for detailed metabolic characterization. They came to the clinical research centre after an overnight fast. Body weight, height, body mass index (BMI), waist circumference and blood pressure were measured. An intravenous cannula was inserted in an antecubital vein for collection of blood to measure glycosylated haemoglobin $A_{1 c}\left(H_{b A} A_{1 c}\right)$, serum insulin, plasma glucose, low-density lipoprotein (LDL) and high-density lipoprotein (HDL) cholesterol, triglyceride, aspartate aminotransferase (AST) and alanine aminotransferase (ALT) concentrations, and for genotyping of PNPLA3 at rs738409. After basal blood sampling and anthropometric measurements, a 75-g oral glucose tolerance test was performed, during which both glucose and insulin concentrations at 0 , 30 and 120 min were captured. HOMA-IR was used as a proxy for insulin resistance [26]. The Matsuda insulin sensitivity index was applied as another measure of insulin sensitivity and was calculated from insulin and glucose concentrations assessed at 0 , 30 and 120 minutes during the oral glucose tolerance test [27]. After genotyping consecutive patients, we identified 26 subjects lacking the PNPLA3 I148M gene variant (PNPLA3 ${ }^{148 \mid I}$ ), who were divided into those with 'Metabolic NAFLD' and without NAFLD 
('No NAFLD') based on \% of hepatocytes with macroscopic steatosis in the liver biopsies (see below).

Adipose tissue inflammation. To determine whether coagulation factor activities are associated with pro- or anti-inflammatory cytokines or adipokines in subjects lacking the gene variant i.e. in PNPLA3 ${ }^{148 \mid}$ subjects, we obtained needle biopsies of adipose tissue from the abdominal region and measured coagulation factor activities in 26 such subjects [8]. Gene expression of pro-inflammatory markers [the macrophage marker cluster of differentiation 68 (CD68), monocyte chemoattractant protein $1(M C P-1)$ and tumor necrosis factor alpha $(T N F-\alpha)]$ and of anti-inflammatory markers $[A D I P O Q$ and Twist-related protein-1 (TWIST1)] were measured in the adipose tissue biopsies, and serum MCP-1 and adiponectin concentrations in blood samples collected after an overnight fast (see below). The subjects were also characterized with respect to their clinical and biochemical features (Supplementary Table 3).

All studies were conducted in accordance with the Declaration of Helsinki. Each participant provided written informed consent after being explained the nature and potential risks of the study. The ethics committee of the Helsinki University Central Hospital approved the study protocol.

\section{Methods}

Liver fat ( $\left.{ }^{1} H-M R S\right)$. In subjects not undergoing bariatric surgery ( $\left.n=92\right)$, liver fat content was determined by proton magnetic resonance spectroscopy $\left({ }^{1} \mathrm{H}-\mathrm{MRS}\right)$ and the intensity differences arising from various acquisition parameters and localization techniques were normalized as previously described [28]. Liver fat content was expressed as a mass fraction [29]. 
Liver biopsies and histology. During bariatric surgery, wedge biopsies of the liver were obtained as described [30]. Part of the biopsy was sent to the pathologist for histological assessment. The rest of the biopsy was snap-frozen in liquid nitrogen for subsequent isolation of RNA and analysis of gene expression using qPCR (see below). Liver histology was analysed by an experienced liver pathologist in a blinded fashion as proposed by Brunt et al [31]. NAFLD was diagnosed based on histology as macroscopic steatosis in $>10 \%$ of hepatocytes [32].

Subcutaneous adipose tissue biopsies. Needle biopsies of subcutaneous abdominal adipose tissue were obtained under local anaesthesia with $1 \%$ lidocain at the metabolic study visit, as previously described [33]. The adipose tissue samples were immediately frozen in liquid nitrogen and stored at $-80^{\circ} \mathrm{C}$ until analysis.

Analysis of gene expression in adipose tissue and the liver. The relative mRNA concentrations of genes of interest in the liver and in the adipose tissue biopsies were quantified by qPCR. Total RNA was isolated from liver tissue by the RNeasy Mini Kit (Qiagen, Valencia, CA) and from subcutaneous adipose tissue by using the RNeasy Lipid Tissue Mini Kit (Qiagen). The RNA (500 ng) was reverse transcribed using the SuperScript VILO cDNA synthesis kit (Invitrogen, Carlsbad, CA). Each sample was amplified in duplicate for quantification of mRNA concentration of the coagulation factors $(F 8, F 9, F 11, F 13 A 1$, and $F G G$ encoding FVIII, FIX, FXI, FXIII-A, and fibrinogen $\mathrm{Y}$ chain), pro-inflammatory (CD68, MCP-1, TNF- $\alpha$ ) and anti-inflammatory (ADIPOQ encoding adiponectin, TWIST1) markers on a LightCycler ${ }^{\circledast} 480$ (Roche Diagnostics, Rotkreuz, Switzerland) using the SYBR-Green kit (Roche Diagnostics). The hepatic expression of coagulation markers was normalized to that of the housekeeping gene 
succinate dehydrogenase complex, subunit $\mathrm{A}(\mathrm{SDHA})$. The adipose tissue expression of inflammation markers was normalized to that of the housekeeping gene acidic ribosomal phosphoprotein 36B4 (36B4). Primer sequences are shown in Supplementary Table 4

Analytical procedures. Fasting plasma glucose was measured using a hexokinase method on an autoanalyser (Roche Diagnostics Hitachi 917, Hitachi Ltd., Tokyo, Japan). Fasting serum insulin concentrations were determined by time-resolved fluoroimmunoassay using Insulin Kit (AUTOdelfia, Wallac, Turku, Finland). $\mathrm{HbA}_{1 \mathrm{c}}$ was measured by high-pressure liquid chromatography using a fully automated Glycosylated Hemoglobin Analyzer System (BioRad, Richmond, CA). LDL and HDL cholesterol, and triglyceride concentrations were measured with respective enzymatic kits from Roche Diagnostics using an autoanalyzer (Roche Diagnostics Hitachi 917, Hitachi Ltd., Tokyo, Japan). Serum creatinine, ALT and AST concentrations were determined as recommended by the European Committee for Clinical Laboratory Standards. Serum adiponectin was measured using the Human Adiponectin ELISA kit from B-Bridge International (Cupertino, CA) and serum MCP-1 using an ELISA kit from Quantikine, P\&D Systems (Minneapolis, MN).

Blood samples for coagulation assay were collected after an overnight fast from an antecubital vein into tubes containing $0.129 \mathrm{~mol} / \mathrm{l}$ citrate. Plasma was separated by centrifugation for $20 \mathrm{~min}$ at $2245 \mathrm{~g}$ in room temperature, and frozen in aliquots that were stored at $-70{ }^{\circ} \mathrm{C}$ until assayed. Prothrombin time (PT, \% of activity of normal), activated partial thromboplastin time (APTT, in seconds), and activities of fibrinogen, VWF, FVII, FVIII, FIX, FXI, FXII and FXIII were measured using the BCS $^{\circledR}$ XP coagulation analyser (Siemens Healthcare Diagnostics, Marburg, Germany) at the 
coagulation laboratory of Helsinki University Hospital (HUSLAB) as previously described [15]. PT was measured with Owren method and the Nycotest ${ }^{\circledR}$ PT reagent (Axis-Shield, Oslo, Norway), APTT with the Actin ${ }^{\circledR}$ FSL reagent (Siemens Healthcare Diagnostics) and fibrinogen with a modification of the Clauss method (Multifibren ${ }^{\circledR} \mathrm{U}$; Siemens Healthcare Diagnostics). D-dimer was assessed using an immunoturbidimetric assay (Tina-quant D-Dimer ${ }^{\circledR}$, Roche Diagnostics, Mannheim, Germany). VWF ristocetin cofactor (VWF:RCo) activity was measured using the $\mathrm{BC}^{\circledR}$ von Willebrand Reagent, FVII activity using Dade $^{\circledR}$ Innovin $^{\circledR}$ and Coagulation Factor VII Deficient Plasma, and FXIII activity using Berichrom ${ }^{\circledR}$ FXIII, all the reagents from Siemens Healthcare Diagnostics. For one-stage FVIII, FIX, FXI and FXII activity measurements we used Pathromtin SL ${ }^{\circledR}$ and specific coagulation factor deficient plasma (all from Siemens Healthcare Diagnostics). The local reference ranges were as follows: PT 70-130 \%, APTT 23-33 s, fibrinogen 1.7-4.0 g/l, D-dimer <0.5 mg/l, VWF:RCo 44-183 IU/dl (\%), FVII 76-170 \%, FVIII 52-148 \%, FIX 67-135 \%, FXI 60-120 \%, FXII 60-150 \% and FXIII 76-156 \%.

Statistical analyses. Distribution of continuous variables was tested for normality using the D'Agostino-Pearson normality test. Data are shown as mean \pm SEM or, for nonnormally distributed data, as median followed by the $25^{\text {th }}$ and $75^{\text {th }}$ percentiles. Mean values between the groups were compared with the unpaired $t$-test and median with Mann-Whitney $U$ test, or with the one-way analysis of variance and Kruskal-Wallis $\mathrm{H}$ test in the case of three or more groups. For categorical variables, Fisher's exact test was used. We performed logarithmic transformation for non-normally distributed data when needed. Correlation analyses were performed using Pearson's and Spearman's correlation coefficient and partial correlation. The Grubbs' test with an alpha-value 0.05 was used to identify outliers that were then excluded. GraphPad Prism version 6.00 
for Mac (GraphPad Software, San Diego, CA) and IBM SPSS Statistics 22.0 for Mac (IBM SPSS, Chicago, IL) were used to perform the statistical analyses. A p-value of less than 0.05 was considered statistically significant. 


\section{Results}

Subject characteristics and circulating coagulation factor activities

The 'IR' and 'IS' groups were comparable with respect to age, gender and PNPLA3 genotype (Table 1). Subjects in the 'IR' group had higher liver fat content (Figure 1A), fasting glucose and insulin, HOMA-IR, and triglyceride concentrations than the 'IS' group (Table 1). The PNPLA3 ${ }^{148 \mathrm{MM} / \mathrm{Ml}}$ group had greater liver fat content than the PNPLA3 ${ }^{148 \mid l}$ group (Figure $1 \mathrm{~A}$ ) but there were no differences in fasting glucose or insulin, HOMA-IR or triglyceride concentrations between these groups (Table 1).

Coagulation activities of FVIII (Figure 1B), FIX (Figure 1C), FXI (108 \pm 2 vs. $96 \pm 3 \%$, $p=0.001)$, FXII (111 \pm 3 vs. $100 \pm 4 \%, p=0.02)$, FXIII (105 \pm 3 vs. $96 \pm 3 \%, p=0.05)$ VWF:RCo (124 \pm 7 vs. $99 \pm 7 \%, p=0.01)$, the concentration of fibrinogen $(4.2 \pm 0.2$ vs. $3.6 \pm 0.2 \mathrm{~g} / \mathrm{l}, p=0.01)$ and PT (124 \pm 3 vs. $114 \pm 3 \%, p=0.01)$ were all significantly higher and APTT (Figure 1D) shorter in the 'IR' than the 'IS' group. Activities of FVII [118 (110-132) vs. $114 \%(100-129), p=0.18]$ and D-dimer concentrations [0.15 (0.05$0.30)$ vs. $0.08 \mathrm{mg} / \mathrm{l}(0.05-0.20), p=0.20]$ did not differ between 'IR' and 'IS' groups.

In contrast, all coagulation variables were comparable between the PNPLA3 ${ }^{148 \mathrm{MM} / \mathrm{MI}}$ and PNPLA3 ${ }^{148 I I}$ groups: FVII [117 (97-128) vs. 117\% (106-130), p=0.55], FVIII (Figure 1B), FIX (Figure 1C), FXI (102 \pm 3 vs. $103 \pm 2 \%, p=0.86)$, FXII (105 \pm 4 vs. $106 \pm 3 \%$, p=0.80), FXIII (104 \pm 4 vs. $99 \pm 3, p=0.29)$, fibrinogen $(3.9 \pm 0.2$ vs. $4.0 \pm 0.2 \mathrm{~g} / \mathrm{l}$, $p=0.52), V W F: R C o(114 \pm 7$ vs. $110 \pm 7$ IU/dl, $p=0.69)$, PT (121 \pm 4 vs. $117 \pm 2 \%$, $\mathrm{p}=0.43)$, APTT (Figure 1D) and D-dimer $[0.10(0.05-0.30)$ vs. $0.10 \mathrm{mg} / \mathrm{l}(0.05-0.20)$, $p=0.99]$, despite the liver fat distinction. 
The degree of insulin resistance assessed by HOMA-IR correlated positively with activities of FVII, FVIII, FIX, FXI, FXII, FXIII, VWF:RCo, fibrinogen and PT, and inversely with APTT. The relationships between HOMA-IR and activities of FVII, FVIII, FIX, FXI, FXII, VWF:RCo, PT and APTT remained significant after adjustment for age, gender, BMI and PNPLA3 genotype. Correlation coefficients and $p$-values are shown in Supplementary Table 5.

Characteristics of the subjects divided in a $2 \times 2$ fashion based on both the PNPLA3 genotype and insulin sensitivity are shown in Supplementary Table 1. Activities of FVIII, FIX, FXI, fibrinogen and VWF:RCo were increased and APTT was shortened in IR as compared to IS subjects without the PNPLA3 gene variant ('IR and PNPLA3 ${ }^{148 \|}$ ', vs. 'IS and PNPLA3 ${ }^{148 \| l ', ~ S u p p l e m e n t a r y ~ T a b l e ~ 2) . ~ T h e ~ P N P L A 3 ~ g e n o t y p e ~ d i d ~ n o t ~ i n-~}$ fluence the coagulation variables in either IS or IR subjects (Supplementary Table 2).

Expression of F8, F9, FGG, F11 and F13A in the human liver

Characteristics of the subjects lacking the PNPLA3 I148M gene variant who underwent a liver biopsy $(n=26)$ are shown in Table 2. The subjects with 'Metabolic NAFLD' as compared to those without NAFLD had higher fasting serum insulin, HOMA-IR and plasma ALT, and lower Matsuda insulin sensitivity index (Table 2). The groups were equally obese and did not differ in age or gender.

The gene expression of $F 8, F 9$ and $F G G$ were higher in the 'Metabolic NAFLD' than in the 'No NAFLD' group (Figure 2). Expression of $F 11(1.1 \pm 0.1$ vs. $1.0 \pm 0.1, p=0.11$ ) and F13A1 (1.2 \pm 0.1 vs. $1.0 \pm 0.1, p=0.28)$ did not differ between the 'Metabolic NAFLD' and 'No NAFLD' groups. 
Relationship between coagulation factors activities and expression of pro- and antiinflammatory markers in adipose tissue and in serum in subjects lacking the PNPLA3 I148M gene variant (PNPLA3 ${ }^{148 I I)}$

Characteristics of the subjects lacking the PNPLA3 I148M gene variant who underwent an adipose tissue biopsy are shown in Supplementary Table 3. Gene expression of the macrophage marker CD68 in adipose tissue correlated positively with PT \% (Figure 3A), FIX (Figure 3B), FXI $(r=0.44, p<0.05)$ and VWF:RCo $(r=0.40, p<0.05)$ activities, fibrinogen (Figure $3 C$ ), and D-dimer $(r=0.59, p<0.01)$. Gene expression of $M C P-1$ correlated with FVIII $(r=0.53, p<0.01)$, VWF:RCo $(r=0.59, p<0.01)$ and D-dimer $(r=0.60$, $p<0.01)$, and TNF- $\alpha$ with FIX $(r=0.45, p<0.05)$ and FXI $(r=0.47, p<0.05)$. Adipose tissue expression of the anti-inflammatory marker ADIPOQ correlated inversely with FIX ( $r=-$ $0.39, p<0.05)$ and fibrinogen $(r=-0.41, p<0.05)$, and that of TWIST1 with the vitamin Kdependent coagulation factors, PT \% $(r=-0.57, p<0.01)$ and FIX $(r=-0.57, p<0.01)$ and with D-dimer $(r=-0.48, p<0.01)$. Serum MCP-1 correlated positively with VWF:RCo $(r=0.47, p=0.02)$ and serum adiponectin inversely with functional fibrinogen in plasma $(r=-0.43, p=0.04)$. 


\section{Discussion}

In the present study, increased clotting activity characterized insulin-resistant subjects with increased liver fat compared to insulin-sensitive subjects. Subjects with the PNPLA3 I148M gene variant had a similar increase in liver fat as the insulin-resistant subjects in the absence of insulin resistance. Increases in liver fat were also accompanied by increases in serum AST and ALT. All coagulation variables were comparable between carriers and non-carriers of I148M variant, despite distinct amounts of fat in the liver. Subjects with 'Metabolic NAFLD', i.e. those who were lacking the I148M variant but had insulin resistance and fatty liver, had clearly upregulated hepatic expression of $F 8, F 9$ and $F G G$ compared to equally obese subjects without NAFLD. Thus, obesity does not explain increased coagulation factor expression in insulin-resistant subjects with NAFLD. In subjects lacking the PNPLA3 I148M gene variant, adipose tissue pro-inflammatory markers correlated positively and anti-inflammatory markers inversely with activities of FVIII, FIX, FXI, VWF:RCo and functional fibrinogen. These data demonstrate that insulin resistance rather than liver fat influences circulating coagulation factors and their susceptibility for activation. We suggest that adipose tissue inflammation and insulin resistance regulates FVIII, FIX and fibrinogen activities at the level of gene expression in the liver.

Increased FVIII activity is associated with CVD [34], insulin resistance [35] and risk of venous thromboembolism [36]. In the present study, activities of FVIII and its binding protein VWF were elevated in insulin-resistant subjects with increased liver fat but not in carriers of the PNPLA3 I148M variant with a compatible liver fat content. This shows that increased liver fat per se does not explain increased FVIII or VWF:RCo activities in humans. We also found, to our knowledge for the first time in human liver samples, that gene expression of F8, which encodes for FVIII, was upregulated in the 
insulin-resistant subjects with increased liver fat compared to insulin-sensitive with normal liver fat (Fig. 2). FVIII is an acute phase protein, which is transcriptionally responsive to NFKB activation by pro-inflammatory cytokines [37]. The relationship between adipose tissue MCP-1 expression and FVIII activity supports the idea that adipose tissue inflammation, systemic insulin resistance and hepatic acute-phase protein production are closely interrelated $[9-11,38]$.

FIX and FXI activities were increased in subjects with high liver fat content and insulin resistance, but not in PNPLA3 I148M variant carriers with high liver fat without insulin resistance. FIX [39] and FXI [40] are produced almost exclusively by the liver but their expression has not been compared between insulin-resistant and sensitive groups. We found the expression of $F 9$ but not $F 11$ to be upregulated in insulin-resistant subjects with 'Metabolic NAFLD' as compared to insulin-sensitive subjects without NAFLD. Similarly to FVIII, FIX and FXI activities were closely correlated with the markers of inflammation and adipokines in adipose tissue. Previous studies have reported circulating interleukin 6 and high-sensitive C-reactive protein, markers of low-grade inflammation in insulin-resistant subjects [41], to correlate with the activities of FVIII, FIX, FXI, fibrinogen and VWF, and shortened prothrombin time $[42,43]$. These data show that increased FIX and $\mathrm{XI}$ activities reflect obesity/insulin resistance rather than liver fat content per se, and that changes in FIX activity could reflect regulation of gene expression in the liver. However, regulation of FIX activity is complex $[44,45]$, and cannot be determined in a cross-sectional in vivo study.

The liver is the main source of the inhibitory subunit B of FXIII [46], while the active subunit $A$ is expressed in liver, macrophages, monocytes and platelets $[47,48]$. This together with the present data showing elevated FXIII activity but unchanged hepatic 
expression of F13A1 in insulin-resistant subjects implies that FXIII activity is regulated via mechanisms other than those involving changes in hepatic $F 13 A 1$ expression.

The finding of increased fibrinogen concentration in insulin-resistant subjects with increased liver fat is keeping with previous reports in obese subjects with NAFLD compared to less obese subjects without NAFLD [16]. We extend previous data by showing that expression of fibrinogen, especially its $y$ chain, is upregulated in the liver of insulin-resistant subjects with 'Metabolic NAFLD' lacking the PNPLA3 gene variant. Consistent with the idea that the increase in fibrinogen gene expression could be a downstream event, reflecting inflammation in extra-hepatic tissues [23], adipose tissue expression of the macrophage marker CD68 correlated positively and adiponectin inversely with functional fibrinogen in plasma.

The extrinsic coagulation pathway including prothrombin, FVII and FX [49] is triggered by tissue factor, which is closely associated with atherosclerotic plaques [50]. PT measures the activity of this pathway, and APTT assesses the activity of the intrinsic coagulation pathway consisting of prothrombin, FV, VIII, IX, X, XI and XII, and fibrinogen [12]. In the present study, subjects with increased liver fat and insulin resistance had shortened PT (i.e. \% of normal was increased) and APTT, implying that the changes in individual coagulation factors indeed translated into a significantly enhanced clotting activity.

Coagulation factor activities and insulin sensitivity were unchanged between subjects with and without PNPLA3 I148M variant, despite distinct liver fat contents. This finding accords with multiple studies showing that the PNPLA3 I148M gene variant predisposes to liver disease but not insulin resistance or risks of type 2 diabetes or CVD [2]. 
Taken together these data show that circulating coagulation factor activities are upregulated in subjects who have both an increased liver fat content and insulin resistance ('Metabolic NAFLD') but not in subjects who merely have an increased liver fat content due to the I148M PNPLA3 gene variant ('PNPLA3 NAFLD'). Therefore, the patient who has 'Metabolic NAFLD' is likely to be at greater risk of thrombosis while the patient with 'PNPLA3 NAFLD' is not at such risk. 


\section{What is known on this topic?}

- In non-alcoholic fatty liver disease (NAFLD), activities of coagulation factors are elevated. These changes may increase the risk of venous thrombosis and of atherothrombotic vascular disease.

- It is unknown whether the increment of coagulation factor activities in NAFLD is due to obesity/insulin resistance and associated adipose tissue inflammation or due to increased liver fat content per se.

\section{What this paper adds?}

- Clotting activity characterized insulin-resistant subjects with increased liver fat but not those with increased liver fat due to the PNPLA3 I148M variant. This indicates that obesity/insulin resistance rather than an increase in liver fat per se is associated with a procoagulant plasma profile.

- Hepatic gene expression of coagulation factors FVIII, FIX and fibrinogen is upregulated in insulin-resistant subjects with NAFLD.

- The degree of insulin resistance and adipose tissue inflammation correlate with activities of coagulation factors.

\section{Acknowledgements}

Acknowledgements We gratefully acknowledge Anne Salo, Aila Karioja-Kallio, Mia Urjansson, Eeva Jääskeläinen, Pentti Pölönen and Malin Svensson for excellent technical assistance, and the volunteers for their help.

Disclosures Authors do not have conflicts of interest regarding to this study. 


\section{References}

1. European Association for the Study of the Liver (EASL). Electronic address:

easloffice@easloffice.eu, European Association for the Study of Diabetes (EASD), European Association for the Study of Obesity (EASO). EASL-EASD-EASO clinical practice guidelines for the management of non-alcoholic fatty liver disease. J Hepatol. 2016;64:1388-402.

2. Yki-Jarvinen H. Non-alcoholic fatty liver disease as a cause and a consequence of metabolic syndrome. Lancet Diabetes Endocrinol. 2014;2:901-10.

3. Horvei LD, Grimnes G, Hindberg K, Mathiesen EB, Njolstad I, Wilsgaard T, Brox J, Braekkan SK, Hansen JB. C-reactive protein, obesity, and the risk of arterial and venous thrombosis. J Thromb Haemost. 2016;14:1561-71.

4. Romeo S, Kozlitina J, Xing C, Pertsemlidis A, Cox D, Pennacchio LA, Boerwinkle E, Cohen JC, Hobbs HH. Genetic variation in PNPLA3 confers susceptibility to nonalcoholic fatty liver disease. Nat Genet. 2008;40:1461-5.

5. Kotronen A, Johansson LE, Johansson LM, Roos C, Westerbacka J, Hamsten A, Bergholm R, Arkkila P, Arola J, Kiviluoto T, Fisher RM, Ehrenborg E, Orho-Melander M, Ridderstrale M, Groop L, Yki-Jarvinen H. A common variant in PNPLA3, which encodes adiponutrin, is associated with liver fat content in humans. Diabetologia. 2009;52:1056-60.

6. He S, McPhaul C, Li JZ, Garuti R, Kinch L, Grishin NV, Cohen JC, Hobbs HH. A sequence variation (I148M) in PNPLA3 associated with nonalcoholic fatty liver disease disrupts triglyceride hydrolysis. J Biol Chem. 2010;285:6706-15.

7. Sookoian S, Pirola CJ. Meta-analysis of the influence of I148M variant of patatin-like phospholipase domain containing 3 gene (PNPLA3) on the susceptibility and histological severity of nonalcoholic fatty liver disease. Hepatology. 2011;53:1883-94. 
8. Lallukka S, Sevastianova K, Perttila J, Hakkarainen A, Orho-Melander M, Lundbom N, Olkkonen VM, Yki-Jarvinen H. Adipose tissue is inflamed in NAFLD due to obesity but not in NAFLD due to genetic variation in PNPLA3. Diabetologia. 2013;56:886-92.

9. Xu H, Barnes GT, Yang Q, Tan G, Yang D, Chou CJ, Sole J, Nichols A, Ross JS, Tartaglia LA, Chen H. Chronic inflammation in fat plays a crucial role in the development of obesity-related insulin resistance. J Clin Invest. 2003;112:1821-30.

10. Weisberg SP, Hunter D, Huber R, Lemieux J, Slaymaker S, Vaddi K, Charo I, Leibel RL, Ferrante AW,Jr. CCR2 modulates inflammatory and metabolic effects of high-fat feeding. J Clin Invest. 2006;116:115-24.

11. Kanda H, Tateya S, Tamori Y, Kotani K, Hiasa K, Kitazawa R, Kitazawa S, Miyachi H, Maeda S, Egashira K, Kasuga M. MCP-1 contributes to macrophage infiltration into adipose tissue, insulin resistance, and hepatic steatosis in obesity. J Clin Invest. 2006;116:1494-505.

12. Marder V, Aird W, Bennett J, Schulman S, White GI, editors. Hemostasis and thrombosis: Basic principles and clinical practice. 6th ed. Wolters Kluwer Health/Lippincott Williams \& Wilkins; 2013.

13. Wion KL, Kelly D, Summerfield JA, Tuddenham EG, Lawn RM. Distribution of factor VIII mRNA and antigen in human liver and other tissues. Nature. 1985;317:726-9.

14. Cigolini M, Targher G, Agostino G, Tonoli M, Muggeo M, De Sandre G. Liver steatosis and its relation to plasma haemostatic factors in apparently healthy men--role of the metabolic syndrome. Thromb Haemost. 1996;76:69-73.

15. Kotronen A, Joutsi-Korhonen L, Sevastianova K, Bergholm R, Hakkarainen A, Pietilainen KH, Lundbom N, Rissanen A, Lassila R, Yki-Jarvinen H. Increased coagulation factor VIII, IX, XI and XII activities in non-alcoholic fatty liver disease. Liver Int. 2011;31:176-83. 
16. Targher G, Bertolini L, Scala L, Zoppini G, Zenari L, Falezza G. Non-alcoholic hepatic steatosis and its relation to increased plasma biomarkers of inflammation and endothelial dysfunction in nondiabetic men. role of visceral adipose tissue. Diabet Med. 2005;22:1354-8.

17. Bertina RM. Elevated clotting factor levels and venous thrombosis. Pathophysiol Haemost Thromb. 2003;33:395-400.

18. Lisman T, Caldwell SH, Burroughs AK, Northup PG, Senzolo M, Stravitz RT, Tripodi A, Trotter JF, Valla DC, Porte RJ, Coagulation in Liver Disease Study Group. Hemostasis and thrombosis in patients with liver disease: The ups and downs. J Hepatol. 2010;53:362-71.

19. Weisberg SP, McCann D, Desai M, Rosenbaum M, Leibel RL, Ferrante AW,Jr. Obesity is associated with macrophage accumulation in adipose tissue. J Clin Invest. 2003;112:1796-808.

20. Yamauchi T, Kamon J, Waki H, Terauchi Y, Kubota N, Hara K, Mori Y, Ide T, Murakami K, Tsuboyama-Kasaoka N, Ezaki O, Akanuma Y, Gavrilova O, Vinson C, Reitman ML, Kagechika H, Shudo K, Yoda M, Nakano Y, Tobe K, Nagai R, Kimura S, Tomita M, Froguel P, Kadowaki T. The fat-derived hormone adiponectin reverses insulin resistance associated with both lipoatrophy and obesity. Nat Med. 2001;7:941-6.

21. Pettersson AT, Mejhert N, Jernas M, Carlsson LM, Dahlman I, Laurencikiene J, Arner P, Ryden M. Twist1 in human white adipose tissue and obesity. J Clin Endocrinol Metab. 2011;96:133-41.

22. Westerbacka J, Yki-Jarvinen H, Turpeinen A, Rissanen A, Vehkavaara S, Syrjala M, Lassila R. Inhibition of platelet-collagen interaction: An in vivo action of insulin abolished by insulin resistance in obesity. Arterioscler Thromb Vasc Biol. 2002;22:167-72.

23. Fish RJ, Neerman-Arbez M. Fibrinogen gene regulation. Thromb Haemost. 2012;108:419-26.

24. Souri M, Mokuda S, Inanami H, Osaki T, Takasugi K, Ichinose A. Non-autoimmune combined factor XIII A and B subunit deficiencies in rheumatoid arthritis patients treated with anti-interleukin-6 receptor monoclonal antibody (tocilizumab). Thromb Res. 2016;140:100-5. 
25. Stirling D, Hannant WA, Ludlam CA. Transcriptional activation of the factor VIII gene in liver cell lines by interleukin-6. Thromb Haemost. 1998;79:74-8.

26. Matthews DR, Hosker JP, Rudenski AS, Naylor BA, Treacher DF, Turner RC. Homeostasis model assessment: Insulin resistance and beta-cell function from fasting plasma glucose and insulin concentrations in man. Diabetologia. 1985;28:412-9.

27. DeFronzo RA, Matsuda M. Reduced time points to calculate the composite index. Diabetes Care. 2010;33:e93-0646.

28. Kotronen A, Peltonen M, Hakkarainen A, Sevastianova K, Bergholm R, Johansson LM, Lundbom N, Rissanen A, Ridderstrale M, Groop L, Orho-Melander M, Yki-Jarvinen H. Prediction of non-alcoholic fatty liver disease and liver fat using metabolic and genetic factors. Gastroenterology. 2009; $137: 865-72$.

29. Szczepaniak LS, Nurenberg P, Leonard D, Browning JD, Reingold JS, Grundy S, Hobbs HH, Dobbins RL. Magnetic resonance spectroscopy to measure hepatic triglyceride content: Prevalence of hepatic steatosis in the general population. Am J Physiol Endocrinol Metab. 2005;288:E462-8.

30. Hyysalo J, Mannisto VT, Zhou Y, Arola J, Karja V, Leivonen M, Juuti A, Jaser N, Lallukka S, Kakela P, Venesmaa S, Simonen M, Saltevo J, Moilanen L, Korpi-Hyovalti E, Keinanen-Kiukaanniemi S, Oksa H, Orho-Melander M, Valenti L, Fargion S, Pihlajamaki J, Peltonen M, Yki-Jarvinen H. A population-based study on the prevalence of NASH using scores validated against liver histology. J Hepatol. 2014;60:839-46.

31. Brunt EM, Janney CG, Di Bisceglie AM, Neuschwander-Tetri BA, Bacon BR. Nonalcoholic steatohepatitis: A proposal for grading and staging the histological lesions. Am J Gastroenterol. 1999;94:2467-74. 
32. Petaja EM, Yki-Jarvinen H. Definitions of normal liver fat and the association of insulin sensitivity with acquired and genetic NAFLD-A systematic review. Int J Mol Sci.

2016;17:10.3390/ijms17050633.

33. Yki-Jarvinen H, Nikkila EA, Kubo K, Foley JE. Assay of glucose transport in human fat cells obtained by needle biopsy. Diabetologia. 1986;29:287-90.

34. Meade TW, Cooper JA, Stirling Y, Howarth DJ, Ruddock V, Miller GJ. Factor VIII, ABO blood group and the incidence of ischaemic heart disease. Br J Haematol. 1994;88:601-7.

35. de Lange M, Snieder H, Ariens RA, Andrew T, Grant PJ, Spector TD. The relation between insulin resistance and hemostasis: Pleiotropic genes and common environment. Twin Res. 2003;6:152-61.

36. Luxembourg B, Schmitt J, Humpich M, Glowatzki M, Dressler D, Seifried E, Lindhoff-Last E. Cardiovascular risk factors in idiopathic compared to risk-associated venous thromboembolism: A focus on fibrinogen, factor VIII, and high-sensitivity C-reactive protein (hs-CRP). Thromb Haemost. 2009;102:668-75.

37. Begbie M, Notley C, Tinlin S, Sawyer L, Lillicrap D. The factor VIII acute phase response requires the participation of NFkappaB and C/EBP. Thromb Haemost. 2000;84:216-22.

38. Liaskou E, Wilson DV, Oo YH. Innate immune cells in liver inflammation. Mediators Inflamm. 2012;2012:949157.

39. Tissue expression of $F 9$.[homepage on the Internet]. [cited 23th June, 2016] Available from: http://www.proteinatlas.org/ENSG00000101981-F9/tissue.

40. Tissue expression of F11.[homepage on the Internet]. [cited 23th June, 2016] Available from: http://www.proteinatlas.org/ENSG00000088926-F11/tissue. 
41. Natali A, Toschi E, Baldeweg S, Ciociaro D, Favilla S, Sacca L, Ferrannini E. Clustering of insulin resistance with vascular dysfunction and low-grade inflammation in type 2 diabetes. Diabetes. 2006;55:1133-40.

42. Wannamethee SG, Whincup PH, Rumley A, Lowe GD. Inter-relationships of interleukin-6, cardiovascular risk factors and the metabolic syndrome among older men. J Thromb Haemost. 2007;5:163743.

43. Kaye SM, Pietilainen KH, Kotronen A, Joutsi-Korhonen L, Kaprio J, Yki-Jarvinen H, Silveira A, Hamsten A, Lassila R, Rissanen A. Obesity-related derangements of coagulation and fibrinolysis: A study of obesity-discordant monozygotic twin pairs. Obesity (Silver Spring). 2012;20:88-94.

44. Funnell AP, Crossley M. Hemophilia B leyden and once mysterious cis-regulatory mutations. Trends Genet. 2014;30:18-23.

45. Safdar H, Cheung KL, Vos HL, Gonzalez FJ, Reitsma PH, Inoue Y, van Vlijmen BJ. Modulation of mouse coagulation gene transcription following acute in vivo delivery of synthetic small interfering RNAs targeting HNF4alpha and C/EBPalpha. PLoS One. 2012;7:e38104.

46. Tissue expression of F13B. [homepage on the Internet]. [cited 23th June, 2016] Available from: http://www.proteinatlas.org/ENSG00000143278-F13B/tissue.

47. Wolpl A, Lattke H, Board PG, Arnold R, Schmeiser T, Kubanek B, Robin-Winn M, Pichelmayr R, Goldmann SF. Coagulation factor XIII A and B subunits in bone marrow and liver transplantation. Transplantation. 1987;43:151-3.

48. Cordell PA, Kile BT, Standeven KF, Josefsson EC, Pease RJ, Grant PJ. Association of coagulation factor XIII-A with golgi proteins within monocyte-macrophages: Implications for subcellular trafficking and secretion. Blood. 2010;115:2674-81.

49. OWREN PA. Thrombotest. A new method for controlling anticoagulant therapy. Lancet. $1959 ; 2: 754-8$. 
50. Tremoli E, Camera M, Toschi V, Colli S. Tissue factor in atherosclerosis. Atherosclerosis. 1999;144:273-83. 
Table 1. Characteristics of the study groups.

\begin{tabular}{|c|c|c|c|c|}
\hline & $\begin{array}{c}\text { IS } \\
(n=46)\end{array}$ & $\begin{array}{c}\mathrm{IR} \\
(\mathrm{n}=46)\end{array}$ & $\begin{array}{l}\text { PNPLA3 }{ }^{148 I I} \\
\quad(n=54)\end{array}$ & $\begin{array}{l}\text { PNPLA3 }{ }^{148 M M / M I} \\
\quad(n=38)\end{array}$ \\
\hline HOMA-IR & $1.0(0.6-1.6)$ & $3.6(2.8-4.6) * * *$ & $2.4(1.0-3.3)$ & $2.4(1.1-3.7)$ \\
\hline PNPLA3 ${ }^{14811 /} / P^{2} P L A 3^{148 M M / M I}$ & $27 / 19$ & $27 / 19$ & $54 / 0$ & $0 / 38$ \\
\hline Gender (men/women) & $22 / 24$ & $23 / 23$ & $25 / 29$ & $20 / 18$ \\
\hline Age (years) & $40(26-52)$ & $43(34-54)$ & $40(27-50)$ & $43(31-56)$ \\
\hline $\mathrm{BMI}\left(\mathrm{kg} / \mathrm{m}^{2}\right)$ & $28.2 \pm 0.7$ & $33.4 \pm 0.6^{* * *}$ & $31.0 \pm 0.7$ & $30.5 \pm 0.8$ \\
\hline Waist-to-hip ratio & $0.91 \pm 0.01$ & $0.99 \pm 0.01^{* * *}$ & $0.95 \pm 0.01$ & $0.95 \pm 0.02$ \\
\hline $\begin{array}{l}\text { Smoking status (current/ex- } \\
\text { smoker/never) }\end{array}$ & $4 / 0 / 42$ & $6 / 0 / 40$ & $5 / 0 / 49$ & $5 / 0 / 33$ \\
\hline fS-insulin (mU/l) & $4.2(2.7-6.7)$ & $14.1(12.2-17.1)^{\star \star \star}$ & $10.4(3.9-13.4)$ & $8.8(4.5-14.3)$ \\
\hline fP-glucose (mmol/l) & $5.4 \pm 0.1$ & $5.7 \pm 0.1$ * & $5.5 \pm 0.1$ & $5.6 \pm 0.1$ \\
\hline $\mathrm{HbA}_{1 \mathrm{c}}(\%)$ & $5.5 \pm 0.1$ & $5.7 \pm 0.1$ * & $5.6 \pm 0.1$ & $5.6 \pm 0.1$ \\
\hline fP-triglycerides $(\mathrm{mmol} / \mathrm{l})$ & $1.0(0.7-1.5)$ & $1.6(1.2-2.2)^{* * *}$ & $1.3(0.9-1.9)$ & $1.2(0.9-1.7)$ \\
\hline fP-HDL cholesterol $(\mathrm{mmol} / \mathrm{l})$ & $1.5(1.3-1.7)$ & $1.3(1.1-1.5)^{* *}$ & $1.4(1.1-1.6)$ & $1.3(1.1-1.6)$ \\
\hline fP-LDL cholesterol $(\mathrm{mmol} / \mathrm{l})$ & $2.9(2.3-3.4)$ & $3.1(2.6-3.5)$ & $2.9(2.3-3.4)$ & $3.0(2.5-3.5)$ \\
\hline Leukocyte count $\left(10^{9} / \mathrm{l}\right)$ & $5.5(4.7-6.6)$ & $6.5(5.7-7.3) * *$ & $6.0(5.0-7.0)$ & $5.8(5.0-7.2)$ \\
\hline P-AST (U/l) & $25(20-31)$ & $30(24-45)^{* *}$ & $25(21-33)$ & $31(25-46) *$ \\
\hline P-ALT (U/l) & $22(17-46)$ & $39(24-81)^{* * *}$ & $26(19-53)$ & $34(19-80)$ \\
\hline P-AST/P-ALT & $1.1 \pm 0.1$ & $0.8 \pm 0.1^{* * *}$ & $0.9 \pm 0.1$ & $1.0 \pm 0.1$ \\
\hline
\end{tabular}


Data are shown as mean \pm SEM or median followed by the $25^{\text {th }}$ and $75^{\text {th }}$ percentile. ${ }^{*} p<0.05,{ }^{* *} p<0.005,{ }^{* * *} p<0.0005$. Abbreviations: ALT, alanine aminotransferase; AST, aspartate aminotransferase; $\mathrm{BMI}$, body mass index; fP, fasting plasma; fS, fasting serum; $\mathrm{HbA}_{1 c}$, glycosylated hemoglobin $\mathrm{A}_{1 c} ; \mathrm{HDL}$, high-density lipoprotein; HOMA-IR, homeostatic model assessment of insulin resistance; IR, insulin-resistant; IS, insulinsensitive; LDL, low-density lipoprotein; P, plasma. 
Table 2. Characteristics of subjects undergoing liver biopsies.

\begin{tabular}{|c|c|c|}
\hline & $\begin{array}{l}\text { No NAFLD } \\
(n=13)\end{array}$ & $\begin{array}{c}\text { Metabolic NAFLD } \\
(n=13)\end{array}$ \\
\hline HOMA-IR & $1.7(1.2-3.2)$ & $4.6(2.9-6.9) * *$ \\
\hline Matsuda ISI & $79(50-145)$ & $35(24-59)$ * \\
\hline PNPLA3 ${ }^{148 \|} /$ PNPLA3 ${ }^{148 \mathrm{MM} / \mathrm{MI}}$ & $13 / 0$ & $13 / 0$ \\
\hline Gender (men/women) & $4 / 9$ & $6 / 7$ \\
\hline Age (years) & $44 \pm 1$ & $44 \pm 2$ \\
\hline BMI $\left(\mathrm{kg} / \mathrm{m}^{2}\right)$ & $45.7 \pm 1.7$ & $45.7 \pm 0.9$ \\
\hline Waist circumference $(\mathrm{cm})$ & $130 \pm 4$ & $137 \pm 4$ \\
\hline Waist-to-hip ratio & $0.99 \pm 0.04$ & $1.02 \pm 0.03$ \\
\hline $\begin{array}{l}\text { Smoking status (current/ex- } \\
\text { smoker/never) }\end{array}$ & $3 / 5 / 5$ & $3 / 4 / 6$ \\
\hline fP-glucose $(\mathrm{mmol} / \mathrm{l})$ & $5.2(4.7-5.9)$ & $5.8(5.3-6.2)$ \\
\hline fS-insulin (mU/l) & $7.9(5.5-12.5)$ & $19.0(12.1-26.6)$ * \\
\hline fS-C-peptide (nmol/l) & $0.87 \pm 0.09$ & $1.41 \pm 0.12^{* *}$ \\
\hline $\mathrm{HbA}_{1 \mathrm{c}}(\%)$ & $5.7 \pm 0.2$ & $6.2 \pm 0.2$ \\
\hline fP-triglycerides (mmol/l) & $1.1(0.8-2.1)$ & $1.5(1.2-2.0)$ \\
\hline fP-HDL cholesterol (mmol/l) & $1.1 \pm 0.1$ & $1.0 \pm 0.1$ \\
\hline Liver fat content (histology, \%) & $3.1 \pm 1.2$ & $45.8 \pm 6.8^{* * *}$ \\
\hline P-AST (U/I) & $31(25-39)$ & $35(28-41)$ \\
\hline P-ALT (U/I) & $34 \pm 3$ & $52 \pm 6$ * \\
\hline
\end{tabular}


Data are shown as mean \pm SEM or median followed by the $25^{\text {th }}$ and $75^{\text {th }}$ percentile. ${ }^{*} p<0.05,{ }^{* *} p<0.005,{ }^{* * *} p<0.0005$. Abbreviations: ALT, alanine aminotransferase; AST, aspartate aminotransferase; $\mathrm{BMI}$, body mass index; fP, fasting plasma; fS, fasting serum; $\mathrm{HbA}_{1 c}$, glycosylated hemoglobin $\mathrm{A}_{1 c} ; \mathrm{HDL}$, high-density lipoprotein; HOMA-IR, homeostasis model assessment of insulin resistance; ISI, insulin sensitivity index; LDL, low-density lipoprotein; NAFLD, non-alcoholic fatty liver disease; P, plasma. 
Figure legends

Figure 1. Liver fat content (A), activities of FVIII (B) and FIX (C), and APTT (D) in insulin-sensitive (IS, n=46) vs. insulin-resistant (IR, $n=46)$ group, and the PNPLA3 ${ }^{148 I I}$ (148II, $n=54)$ vs. the PNPLA3 ${ }^{148 M M / M I}(148 \mathrm{MM} / \mathrm{MI}, \mathrm{n}=38)$ group. Data are shown as mean \pm SEM. ${ }^{*} p<0.05$ and ${ }^{* * *} p<0.0005$. APTT, activated partial thromboplastin time; FIX, coagulation factor VIII; FIX, coagulation factor IX; ${ }^{1} \mathrm{H}-\mathrm{MRS}$, proton magnetic resonance spectroscopy; $\mathrm{P}$, plasma.

Figure 2. Expression of $F 8, F 9$ and $F G G$ relative to the housekeeping gene in the liver of subjects in 'No NAFLD' (white columns, $n=13$ ) and 'Metabolic NAFLD' (grey columns, $n=13$ ) groups. Data are shown as mean \pm SEM. ${ }^{*} p<0.05$ and ${ }^{* *} p<0.005$. F8, coagulation factor VIII; F9, coagulation factor IX; FGG, fibrinogen $\gamma$ chain; NAFLD, nonalcoholic fatty liver disease.

Figure 3. Relationships (Pearson's correlation coefficient) between PT (A), activity of FIX (B) and fibrinogen (C), and adipose tissue expression of CD68 in 26 non-bariatric subjects without the PNPLA3 I148M gene variant. PT, prothrombin time; FIX, coagulation factor IX; P, plasma. 